\title{
$\mathrm{RF}$ 스퍼터링과 이온소스 복합방식에 의한 플라스틱사출금형(SKD11)의 $\mathrm{DLC}$ 막 응용
}

\author{
김미선 ${ }^{*}$, 홍성필
}

(주)케이디엘씨

\section{The Application of DLC(diamond-like carbon) Film for Plastic Injection Mold by Hybrid Method of RF Sputtering and Ion Source}

\author{
Mi-Seon Kim*, Sung-Pill Hong \\ K. DLC CO., LTD. No 424, The O valley(Anyang International Distribution Complex, Ga-dong), \\ 555-9, Hogye-dong, Dongan-gu, Anyang-shi, Gyunggi-do 431-763, Korea
}

(Received June 15, 2009 ; revised July 30, 2009 ; accepted August 30, 2009)

\begin{abstract}
DLC film was synthesized on plastic injection mold(SKD11, $30 \mathrm{~mm} \times 19 \mathrm{~mm} \times 0.5 \mathrm{~mm}$ ) and $\mathrm{Si}(100)$ wafer for $2 \mathrm{~h}$ at $130^{\circ} \mathrm{C}$ under $6 \mathrm{mTorr}$ using hybrid method of rf sputtering and ion source. The obtained film was analysed by Raman spectroscopy, AFM, TEM, Nano indenter and scratch tester, etc. The film was defined as an amorphous phase. In the Raman spectrum, broad peak of $\mathrm{sp}^{2}$-bonded carbon attributed to graphite at $1550 \mathrm{~cm}^{-1}$ were observed, and the ratio of ID( $\mathrm{sp}^{3}$ diamond intensity)/IG( $\mathrm{sp}^{2}$ graphite intensity) was approximately 0.54. The adhesion of DLC film was more than $80 \mathrm{~N}$ with scratch tester when $0.2 \mu \mathrm{m}$ thickness Cr was coated as interlayer. The micro-hardness was distributed at $35 \sim 37 \mathrm{GPa}$. The friction coefficient was $0.02 \sim 0.07$, and surface roughness(Ra) was $0.34 \sim 1.64 \mathrm{~nm}$. The lifetime of DLC coated plastic injection mold using as a connector part in computer was more than 2 times of non-coated mold.
\end{abstract}

Keywords: DLC, RF sputtering, Raman spectroscopy, Friction coefficient, Adhesion

\section{1. 서 론}

최근 전자산업을 비롯한 자동차 및 정보산업의 급진적인 발전과 시장의 수요 증가로 인하여 산업 현장에서 다양한 기능과 형상을 가진 동일 제품을 반복적으로 생산하는 다기능의 금형이 필요하다. 널 리 사용되는 주요 금형으로서는, 사출금형, 프레스 금형, 다이캐스트 및 기타(유리, 분말, 고무, 단조 등)가 있으며, 이들 금형에는 고성능, 고밀도, 수명 연장, 납기단축 및 양산화 등 광범위한 성질과 특 성이 요구된다. 이러한 각종 금형의 정밀도 및 수 명을 연장하기 위하여 현장에서는 금형재료, 표면

\footnotetext{
*Corresponding author. E-mail : kmsdy@hanmail.net
}

처리, 사용조건 등 다양한 측면에서 개선 방안이 모 색되어지고 있다. 그 중에서도 플라즈마를 이용한 표면처리 측면에서 다양한 건식코팅을 이용하는 박막이 주목받고 있으며, 대표적인 박막으로서는 TiN, TiAIN, CrN, DLC 등이 있으며, 특히, 낮은 마 찰계수와 윤활성이 우수한 DLC(diamond-like carbon) 막에 대한 다양한 연구가 실시되고 있다 ${ }^{1-4)}$.

$\mathrm{DLC}$ 는 고경도에 의한 우수한 내마모성과 낮은 마찰계수를 특징으로 하는 카본 코팅막으로서 마찰 과 마모가 공존하는 다양한 분야에 응용 가능하다. 성막법/제조법은 사용되는 탄소계 가스와 고체 원 료에 따라 고주파플라즈마 CVD, 이온화증착법, 스퍼 터링법, 아크이온플레이팅법으로 분류할 수 있다. 이들의 응용은 처리되는 대상품에 따라 적절한 방 
법을 선택하여 실시하고 있다 ${ }^{5-11)}$.

본 연구에서는, 동일조건에서 반복적으로 사용되 는 플라스틱 사출금형(plastic injection mold, SKD11) 에 대해 고주파 스퍼터링(rf sputtering)과 이온소스 (ion source)법의 복합방식을 이용한 DLC막의 합성 과 그 효과에 대하여 조사하였다.

\section{2. 실험방법}

본 연구에 사용된 코팅장비는 고주파 스퍼터링과 이온소스가 혼합된 복합장비로서, 일본 나노테크 (NanoTech,주)사에서 제조하였다. 플라즈마 발생용 전원은, 중간층(interlayer) 혹은 다층(multilayer)을 설계하기 위한 고주파전원(radio frequency power supply) 및 DLC막 코팅을 위한 이온소스용 전원, 기판에 양호한 밀착력을 얻기 위한 고전압펄스바이 어스전원으로 구성되어 있으며, 그림 1에 코팅 장비 의 개략도를 나타내었다.

사용되어진 코팅장비는 챔버계, 배기계, 제어계, 냉각계, 전원계 및 스퍼터링/이온소스계로 구성되어 있으며, 배기계는 고진공을 실현하기 위하여 터보/ 부스터/로터리펌프로 이루어져 있다. 진공도는 고진 공영역에서는 이온게이지(Ion Gauge), 저진공영역 에서는 Convection Gauge를 사용하여 측정하였다.

코팅은, 중간층 혹은 다층을 위해 6 인치의 금속 타켓을 이용한 고주파 스퍼터링에 의하여 증착하였 으며, $\mathrm{DLC}$ 막은 벤젠 $\left(\mathrm{C}_{6} \mathrm{H}_{6}\right)$ 을 도입하여 열필라멘트 에 의해 분해되는 탄소 소스를 피처리물에 고전압 펄스바이어스로서 이온을 가속화시키는 것에 의하 여 실시하였다.

사용한 시편은, 박막분석을 위한 $\mathrm{Si}$ 웨이퍼 $(20 \mathrm{~mm}$ $\times 20 \mathrm{~mm} \times 0.5 \mathrm{~mm})$, 밀착력 혹은 박리정도 등 기계 적인 특성을 분석하기 위한 초경합금(K10, $12 \mathrm{~mm}$ $\times 12 \mathrm{~mm} \times 4 \mathrm{~mm}$ )을 각각 이용하였다. 코팅하기 전에, 초음파세척기에 약 30 분 클리닝 한 후, 온풍 건조 하였다.

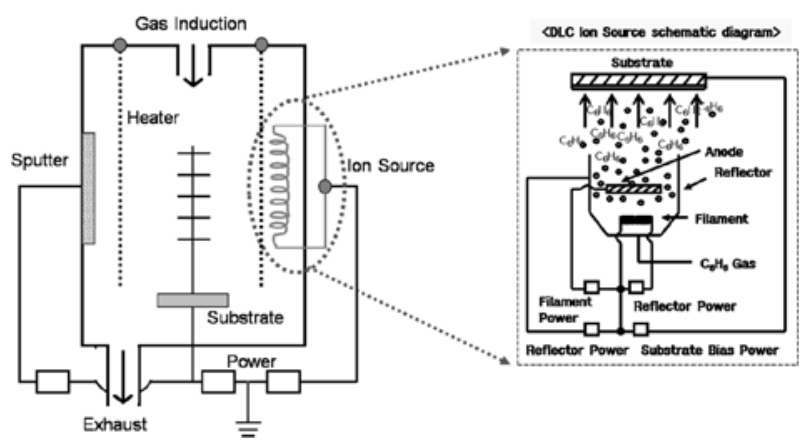

Fig. 1. Schematic diagram of hybrid method of If sputtering and ion source.
먼저, 준비된 상기의 시편을 기판홀더에 셋팅한 다음, 진공도 $2 \times 10^{-6} \mathrm{Torr}$ 까지 배기한 다음, 기판온 도 $130^{\circ} \mathrm{C}$ 로 유지한 후 고주파 스퍼터링에 의해 중 간층 $(\mathrm{Cr}, \mathrm{Si}, \mathrm{Ti})$ 을 그 다음으로 이온소스법에 의해 $\mathrm{DLC}$ 막을 기판전류 $50 \mathrm{~mA}$, 기판전압 $2 \mathrm{kV}$ 필라멘 트 $30 \mathrm{~V} / 10 \mathrm{~mA}$, 가스압 $0.6 \mathrm{mTorr}$ 에서 코팅하였으 며, 전체적으로 코팅막은 1 1.5 $\mu \mathrm{m}$ 로 조절하였다.

증착된 DLC막의 결합구조는 Raman Spectroscopy (Jobin-Yvon, LabRam HR), 표면형상 및 단면구조 는 AFM(Digital Instruments, Nanoscope IIIa), SEM (Hitachi, S-2500C) 및 TEM(FEI, Tecnai G $^{2}$ F30 S-Twin), 단면조성은 GDS(LECO, GDS850A), 미세 경도는 Nano Indenter(MTS), 밀착력과 마찰계수는 scratch tester(CSEM, S/N-A00 14-266 REVETEST) 및 Pin-On-Disk(Neoplus, MPW110)을 이용하여 평 가하였다.

\section{3. 실험결과 및 고찰}

그림 2에 중간층(interlayer)인 $\mathrm{Si}$ 와 $\mathrm{Cr}$ 막에 대하여 $\mathrm{SEM}$ 에 의해 관찰한 표면사진을 나타내었다. 코팅 시간 30 분에서 얻어진 중간층 $\mathrm{Si}$ 및 $\mathrm{Cr}$ 막의 표면은 매우 평탄하며, 미세한 입자로서 형성되어 있음을 볼 수 있다. 또한, 그림 3에 코팅시간 증가에 따라 얻어진 DLC막의 표면사진과 막두께를 나타내었다. 코팅시간 증가에 따라 표면은 매우 평탄하며, 양호 한 표면형상을 보여주고 있다.

코팅시간 증가에 따른 DLC막의 두께변화를 보면, 코팅시간 120 분까지 막두께는 증가하지만, 그 이후 에는 완만하게 증가된다. SEM 및 $\mathrm{AFM}$ 에 의한 표 면형상 관찰결과, 코팅시간 240 분에서 코팅할 경우, 약 $1.5 \sim 2 \mu \mathrm{m}$ 이상에서 일부 국부적으로 박리현상 이 관찰되며 성막율이 저하된다. 이것은 박막내의 과도한 잔류응력에 의한 것으로 추측된다. 그림 4 에 $\mathrm{Si}$ (중간층 $) / \mathrm{DLC}$ 막의 표면형상을 나타내었다.

기판온도 $130^{\circ} \mathrm{C}$ 에서 고주파 스퍼터링과 이온소스 법에 의한 복합방식에 의해 얻어진 $\mathrm{Si}$ (중간층)/DLC 막의 표면은 외관상 검은 광택을 띄고 있으며, 5 회
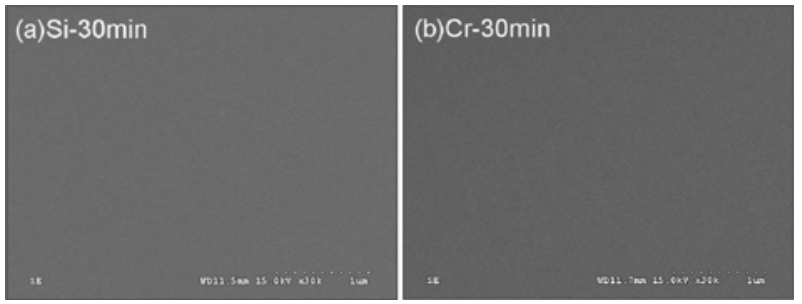

Fig. 2. Surface images of interlayer (a) $\mathrm{Si}$, (b) $\mathrm{Cr}$ film deposited by if sputtering. 


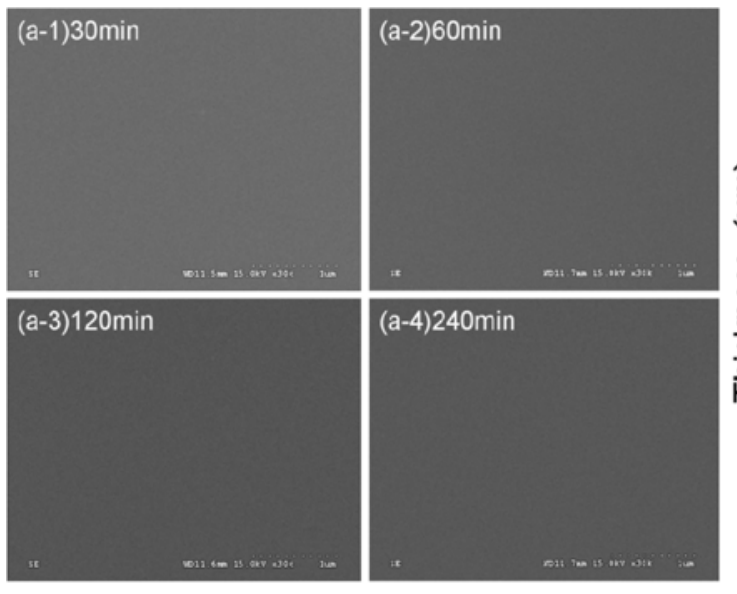

(a) SEM images

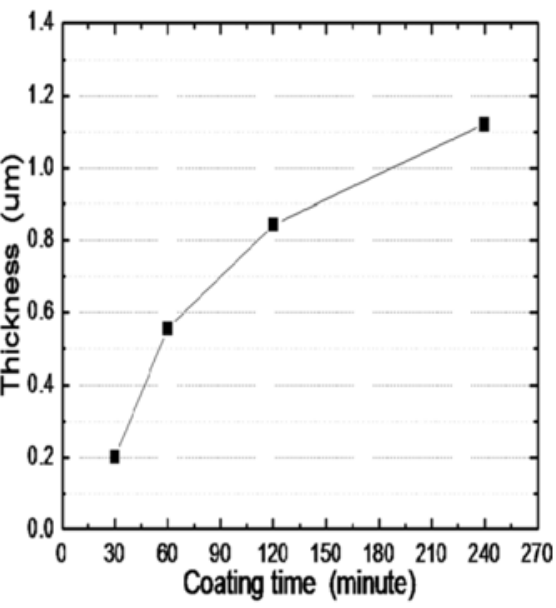

(b) Thickness change

Fig. 3. (a) Surface images, (b) thickness result with increasing of coating time on deposition by ion source.

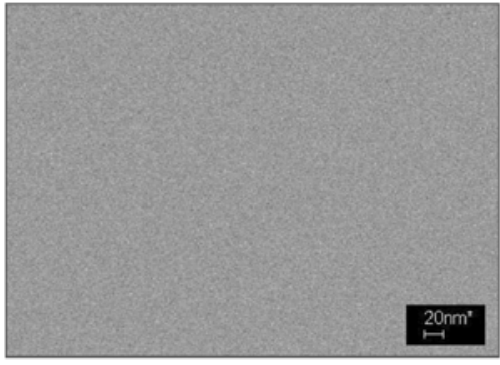

(a) Surface image(SEM)

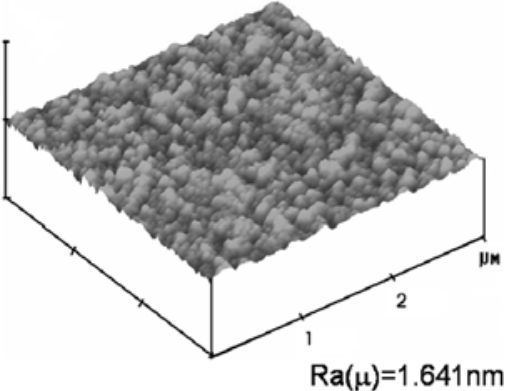

(b) Surface roughness(AFM)

Fig. 4. Surface image and surface roughness of $\mathrm{Si}$ (interlayer)/DLC film.

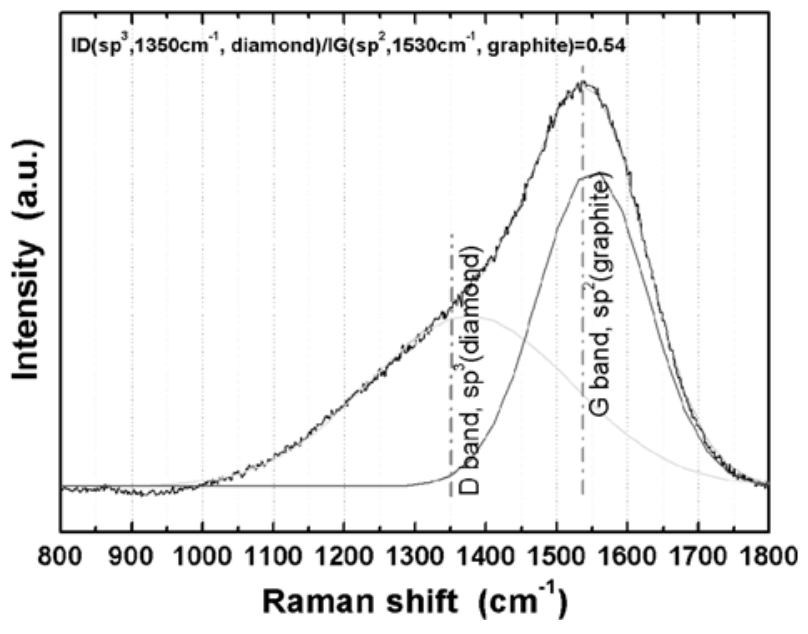

Fig. 5. Raman spectrum and intensity ratio of ID $\left(\mathrm{sp}^{3}\right.$, diamond)/IG ( $\mathrm{sp}^{2}$, graphite) on $\mathrm{Si}$ (interlayer)/DLC film.

측정한 결과, $\mathrm{Ra}$ 는 약 $0.34 \sim 1.64 \mathrm{~nm}$ 로 분포되어 매 우 평탄한 표면을 가지고 있음이 관찰되었다. 또한, 상기의 DLC막에 대하여 Raman산란광을 이용하여 검출된 피크(peak)에 대하여 가우시안(Gaussian)법에 의해 넓은 피크를 분리(fitting)한 결과, $\mathrm{ID}\left(\mathrm{sp}^{3}\right.$, $1350 \mathrm{~cm}^{-1}$, 다이아몬드 $) / \mathrm{IG}\left(\mathrm{sp}^{2}, 1530 \mathrm{~cm}^{-1}\right.$, 흑연 $)$ 강도
비는 약 0.54 로 다이아몬드 성분이 많이 혼재되어 있으며, 전형적인 비정질 DLC막의 넓은 피크 형태 를 보여주고 있다. 그 결과를 그림 5에 나타내었다. 그림 6에 시편으로 사용된 $\mathrm{Si}$ 웨이퍼와 중간층인 $\mathrm{Si}$ 막과의 계면 및 $\mathrm{DLC}$ 막의 미세구조에 대하여 TEM 에 의한 분석결과를 나타내었다. $\mathrm{Si}$ 웨이퍼인 시편 과 중간층 $\mathrm{Si}$ 막 사이의 계면에서는 초기 $\mathrm{Ar}$ 이온에 의한 이온클리닝에 의해 표면에서의 불규칙한 요철 이 관찰되었으며, 전자회절패턴 결과 중간층 $\mathrm{Si}$ 막 과 $\mathrm{DLC}$ 막 계면에서 $\mathrm{SiC}$ 로 추측되는 화합물의 형 성은 관찰되지 않았으며, $\mathrm{Si}$ 의 단일상(single phase) 으로 관찰되었다. 구체적으로는, 중간층 $\mathrm{Si}$ 막과 $\mathrm{DLC}$ 막 사이의 계면에서 $\mathrm{SiC}$ 로 추측되는 화합물의 존 재는 확인되지 않았다. 이것은, 중간층 $\mathrm{Si}$ 가 $\mathrm{DLC}$ 막 초기 성막 단계에 벤젠 $\left(\mathrm{C}_{6} \mathrm{H}_{6}\right)$ 플라즈마에 의한 $\mathrm{SiC}$ 층이 형성된 후에 $\mathrm{DLC}$ 가 형성될 것으로 추측되는 점과는 상이한 결과를 보여주고 있으며, 약 $130^{\circ} \mathrm{C}$ 의 저온에 따른 것으로 판단된다. 또한, $\mathrm{DLC}$ 막은 중앙에 커다란 단일 링의 형성으로 명확한 비정질 상의 카본막으로 확인되었다. 게다가, 그림(b)처럼 중간층 $\mathrm{Si}$ 막 내부에서는 부분적으로 수 $\mathrm{nm}$ 크기의 기공 혹은 유기물로 추측되는 결함이 관찰되었다. 


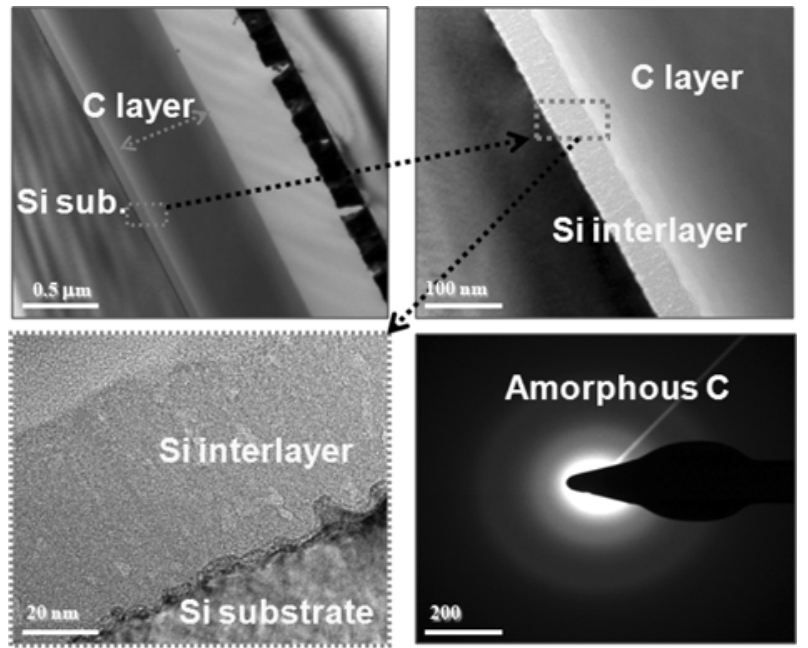

(a)

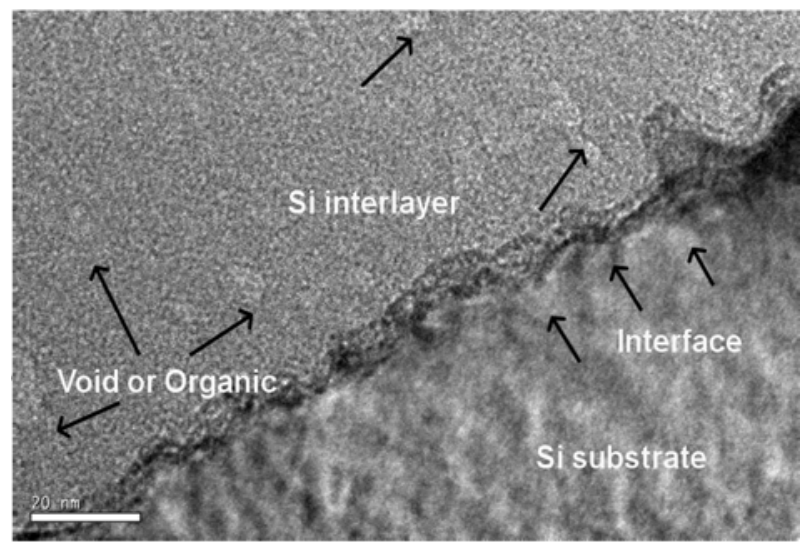

(b)

Fig. 6. TEM images of Si (interlayer)/DLC film: (a) cross section, (b) interface.

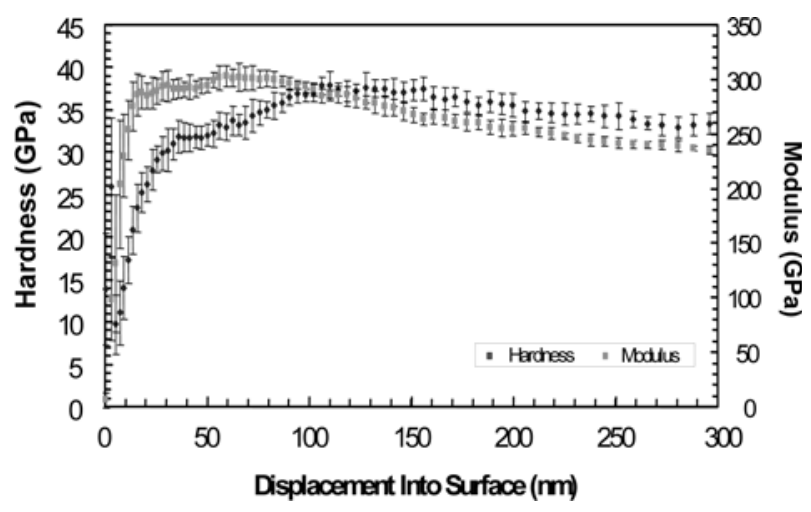

Fig. 7. Micro-hardness of Si (interlayer)/DLC film measured by Nano Indenter.

그림 7에 Nano Indenter(MTS)에 의한 미세경도 측정 결과를 나타내었다. 이때 측정된 $\mathrm{Si}$ (중간층, 30 분)/DLC막(180분)의 전체 두께는 약 $1.3 \mu \mathrm{m}$ 인 막 을 이용하였다. 그림에서 보는 바와 같이, 경도는 약 $35 \sim 37 \mathrm{GPa}$ 에 분포되고 있음을 알 수 있다. 일 반적으로 $\mathrm{DLC}$ 막의 경도는 $20 \sim 30 \mathrm{GPa}$ 이 대부분인 것으로 보고되어 있으나, 본 연구에서 얻어진 DLC

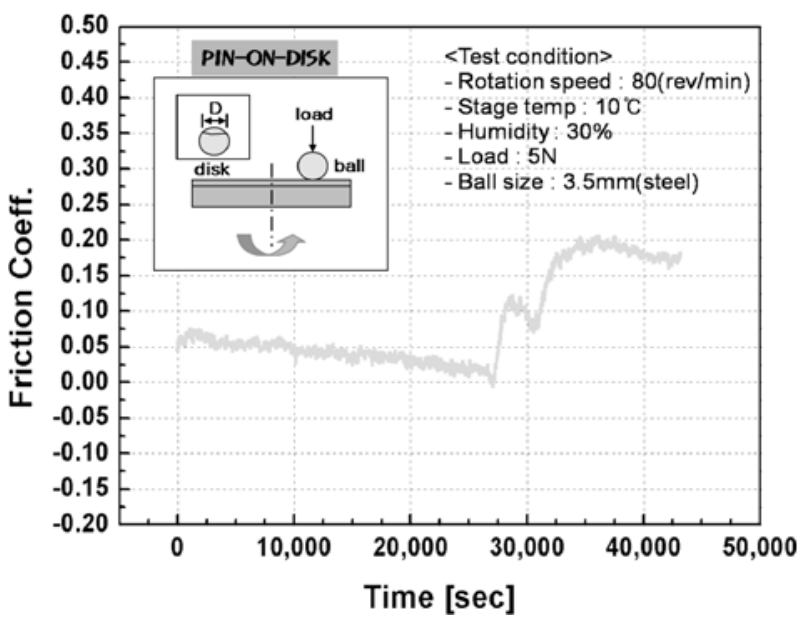

Fig. 8. Friction coefficient of $\mathrm{Si}$ (interlayer)/DLC film measured by Pin-On-Disk.

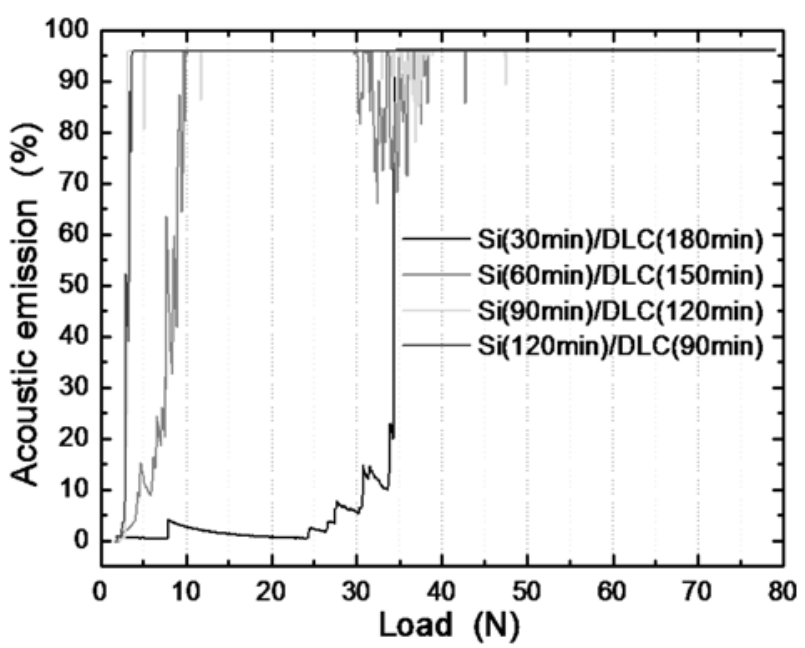

Fig. 9. Adhesion results of $\mathrm{Si}$ (interlayer)/DLC film by scratch tester.

막의 경도는 매우 높으며, 내마모성이 우수함을 간접 적으로 판단할 수 있다. 또한, Pin-On-Disk을 이용 하여 습도 $30 \%$ 인 대기중에서 하중 $5 \mathrm{~N}$ 으로 반복적 인 마모테스트에 의한 마찰계수 $(\mu)$ 측정결과, 약 0.02 0.07이며, 대략 27,000초 이상의 어떤 한계점(시 간)에 이르러 0.1 로 증가하고 있음을 볼 수 있다. 이것은, 매우 낮은 마찰계수로서 자체 낮은 표면조 도를 가지며, 윤활성이 매우 뛰어난 DLC막임을 추 측할 수 있다. 그 결과를 그림 8에 나타내었다.

그림 9에 scratch tester에 의한 밀착력(adhesion) 측정 결과를 나타내었다. 사용되어진 시편은 $\mathrm{Si}$ (중 간층)/DLC막을 코팅한 초경합금(WC-Co)을 이용하 였으며, 다이아몬드 압자의 크기는 $200 \mu \mathrm{m}$ 인 반달 형을 사용하였다. 그림에서 알 수 있듯이, 중간층 $\mathrm{Si}$ 의 두께에 따라 밀착력이 다르게 분포되어 있으 며, 중간층과 $\mathrm{DLC}$ 의 두께에 따라 밀착력이 상이하 며, $\mathrm{Si}$ 막(중간층, 30 분)과 $\mathrm{DLC}(180$ 분)으로 코팅된 


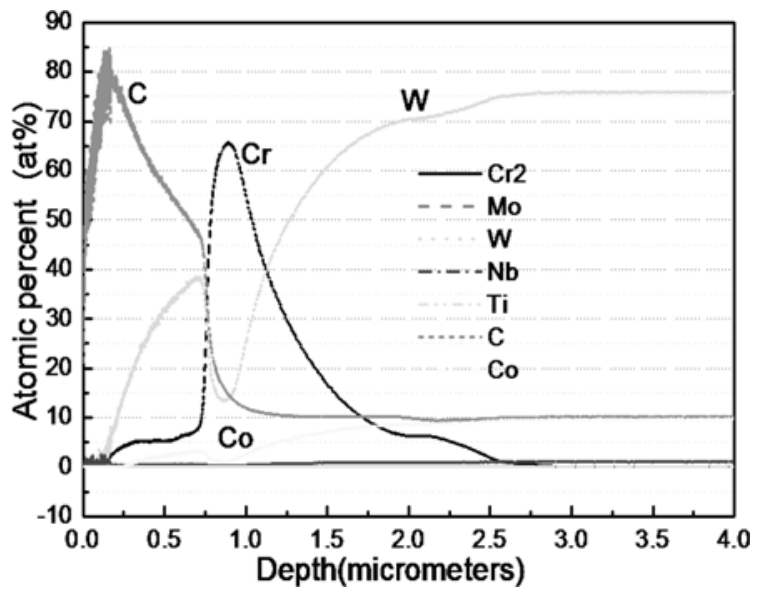

Fig. 10. GDS depth profiles of $\mathrm{Cr}$ (interlayer, $60 \mathrm{~min}$ )/ DLC (120 min) film.

막이 약 $32 \mathrm{~N}$ 으로 가장 양호한 밀착력이 얻어짐을 알 수 있다. 하지만, $\mathrm{Cr}$ (중간층, 60 분 $) / \mathrm{DLC}(120$ 분) 막에서는 $80 \mathrm{~N}$ 이상의 밀착력이 얻어졌다. 이 경우, 스크레치 된 압흔의 흔적을 추적하여 본 결과, 초 경합금 모재의 표면에서 $\mathrm{DLC}$ 막의 스크랩 혹은 박 리로 인한 흔적이 발견되지 않았으며, 단지 다이아 몬드의 압자가 미끄러지는 현상만을 확인할 수 있 었다. 게다가, $\mathrm{Ti}$ (중간층)/DLC막에 의한 밀착력효과 는 약 4 10 N으로 매우 미비하다.

상기 밀착력이 우수한 $\mathrm{Cr}$ (중간층, 60 분)/DLC(120 분)막에 대한 $\mathrm{GDS}$ 에 의한 단면 조성분포를 측정한 결과, 박막구조대로 계면에서 $\mathrm{Cr}$ 층과 그 위에 $\mathrm{DLC}$ 막이 형성되어 있음을 알 수 있다. 그 결과를 그림 10 에 나타내었다.

\section{4. 시제품(플라스틱 사출 금형)의 현장평가}

상기에서 얻어진 결과로부터, 고주파 스퍼터링과 이 온소스법의 복합방식에 의해 밀착력이 우수한 $\operatorname{Cr}($ 중간
층)/DLC막을 플라스틱 사출 금형(SKD11, $30 \mathrm{~mm}$ $\times 19 \mathrm{~mm} \times 0.5 \mathrm{~mm}$ )에 코팅하였다. 평가방법은, 노트북용 부속품으로 사용되는 플라스틱 커넥터(connector) 사출 물용 금형을 제작하여 비코팅, TiN막, TiAIN막, $\mathrm{Cr} / \mathrm{DLC}$ 막을 각각 코팅한 다음, 생산현장에서 실제 제품인 커 넥터 사출물을 생산하는 자동 설비에 셋팅하여 현장 평가를 실시하였다. 여기에서 커넥터 사출물은 LCP라 는 재질의 수지를 녹인 것으로서 약 $340^{\circ} \mathrm{C}$ 의 용융상 태이다. 표 1에 시제품(플라스틱 사출 금형)에 대한 평 가전/후의 외관 및 수명비교 결과를 나타내었다.

단, TiAIN막은 표면조도 불량으로 초기 마모 및 분진 발생으로 제외하였다. 결론적으로, $\mathrm{Cr} / \mathrm{DLC}$ 막 을 코팅하여 적용한 금형의 수명이 비코팅에 비해 약 2 배 이상의 효과를 가져왔으며, 수명 증가 원인 은 윤활성 및 내마모성의 향상 효과가 반복적인 마 찰/마모작용을 방지함과 동시에 양호한 표면조도 및 막자체의 뛰어난 윤활효과에 따른 용착방지에 의한 것으로 추측된다. 한편, 비코팅 및 TiN막에서는 마 모 진행과 함께 마모 스크레치 및 홈부위에서 용착 이 발생되어 있음을 볼 수 있다.

\section{5. 결 론}

고주파 스퍼터링(rf sputtering)과 이온소스(ion source)의 복합방식에 의한 DLC막 코팅을 적용한 결과, 다음과 같은 결론을 얻었다.

(1) Nano Indenter에 의한 미세경도측정 결과, $\mathrm{Si}$ (중 간층)/DLC막에서 약 $35 \sim 37 \mathrm{GPa}$ 로 분포되었다.

(2) Scratch tester에 의한 밀착력 측정 결과, $\operatorname{Cr}(60$ 분)/DLC(120분)막 구조가 가장 양호한 $80 \mathrm{~N}$ 이상으 로 얻어졌으며, $\mathrm{Si}>\mathrm{Ti}$ 순으로 얻어졌다.

(3) TEM에 의한 계면 및 박막분석 결과, 중간층 $\mathrm{Si}$ 막과 $\mathrm{DLC}$ 막 사이의 계면에서의 화합물의 존재는 확인되지 않았으며, 비정질의 카본막으로 확인되었다.

Table 1. The comparison of appearances and lifetime before/after field test for samples (plastic injection mold)

\begin{tabular}{|c|c|c|c|}
\hline & Non-Coationg (SKD11) & SKD11+TiN & $\mathrm{SKD} 11+\mathrm{Cr} / \mathrm{DLC}$ \\
\hline Before & $\underset{\text { Non-Coating }}{-}$ & $\frac{-[-}{\text { TiN }}$ & $\frac{-}{\text { DLC }}$ \\
\hline After & Non-Coating & $\frac{1}{\mathrm{TiN}}$ & DLC \\
\hline Shot & 179,650 & 227,450 & 420,350 \\
\hline Lifetime & 1(standard) & 1.27 & 2.34 \\
\hline
\end{tabular}


(4) Raman spectroscopy에 의한 결합구조 분석 결 과, 전형적인 $\mathrm{DLC}$ 막의 브로드한 라만피크를 보여 주고 있으며, $\mathrm{ID}\left(\mathrm{sp}^{3}\right.$, 다이아몬드성분 $) / \mathrm{IG}\left(\mathrm{sp}^{2}\right.$, 흑연 성분)의 강도비는 약 0.54 였다. 게다가, $\mathrm{AFM}$ 에 의 해 측정한 표면조도 $(\mathrm{Ra})$ 는 $0.34 \sim 1.64 \mathrm{~nm}$ 이며, 마찰 계수는 0.02 0.07로 확인되었다.

(5) 시제품(플라스틱 사출 금형) 수명비교 결과, $\mathrm{Cr} / \mathrm{DLC}$ 막을 코팅하여 적용한 금형의 수명은 비코 팅에 비해 2배 이상의 효과를 가져왔다.

\section{후 기}

본 연구는 중소기업 기술혁신개발사업(S1036312)의 지원으로 이루어졌습니다.

\section{참고문헌}

1. 김미선, 홍성필, 김현구, 한국표면공학회 추계학술
발표회 초록집, (2007) 164.

2. G. J. Vadentop, M. Kawasaki, K. Kobayashi, G. A. Somorjai, J. Vac. Sci. Technol., A9 (1991) 1157.

3. N. Savvides, J. Appl. Phys., 59 (1986) 4133.

4. B. A. Banks, S. K. Rutledge, J. Vac. Sci. Technol., 21 (1982) 807.

5. C. B. Collins, F. Davanloo, E. M. Juengerman, W. R. Osborn, D. R. Jander, Appl. Phys. Lett., 54 (1989) 216.

6. W. D. Munz, Surf. Coat. Technol., 48 (1991) 81.

7. W. D. Sproul, M. E. Graham, M. S. Wong, P. J. Rudnik, Surf. Coat. Technol., 61 (1993) 139.

8. J. A. Thornton, A. S. Perfold, Thin Film Process, edited by J.L. Vossen and W. Kern, Academic Press, (1978) 75.

9. S. Schiller, U. Heisig, K. Goedicke, Thin Solid Films, 40 (1977) 327.

10. J. A. Thornton, J. Vac. Sci. Technol., 46 (1997) 267.

11. W. D. Davis, H. C. Miller, J. Appl. Phys., 40 (1969) 2212. 